Supplement of Atmos. Meas. Tech., 14, 4947-4957, 2021

https://doi.org/10.5194/amt-14-4947-2021-supplement

(C) Author(s) 2021. CC BY 4.0 License.

(c) (i)

Atmospheric
Measurement
Techniques

Supplement of

\title{
Rethinking the correction for absorbing aerosols in the OMI- and TROPOMI-like surface UV algorithms
}

\author{
Antti Arola et al. \\ Correspondence to: Antti Arola (antti.arola@fmi.fi)
}

The copyright of individual parts of the supplement might differ from the article licence. 

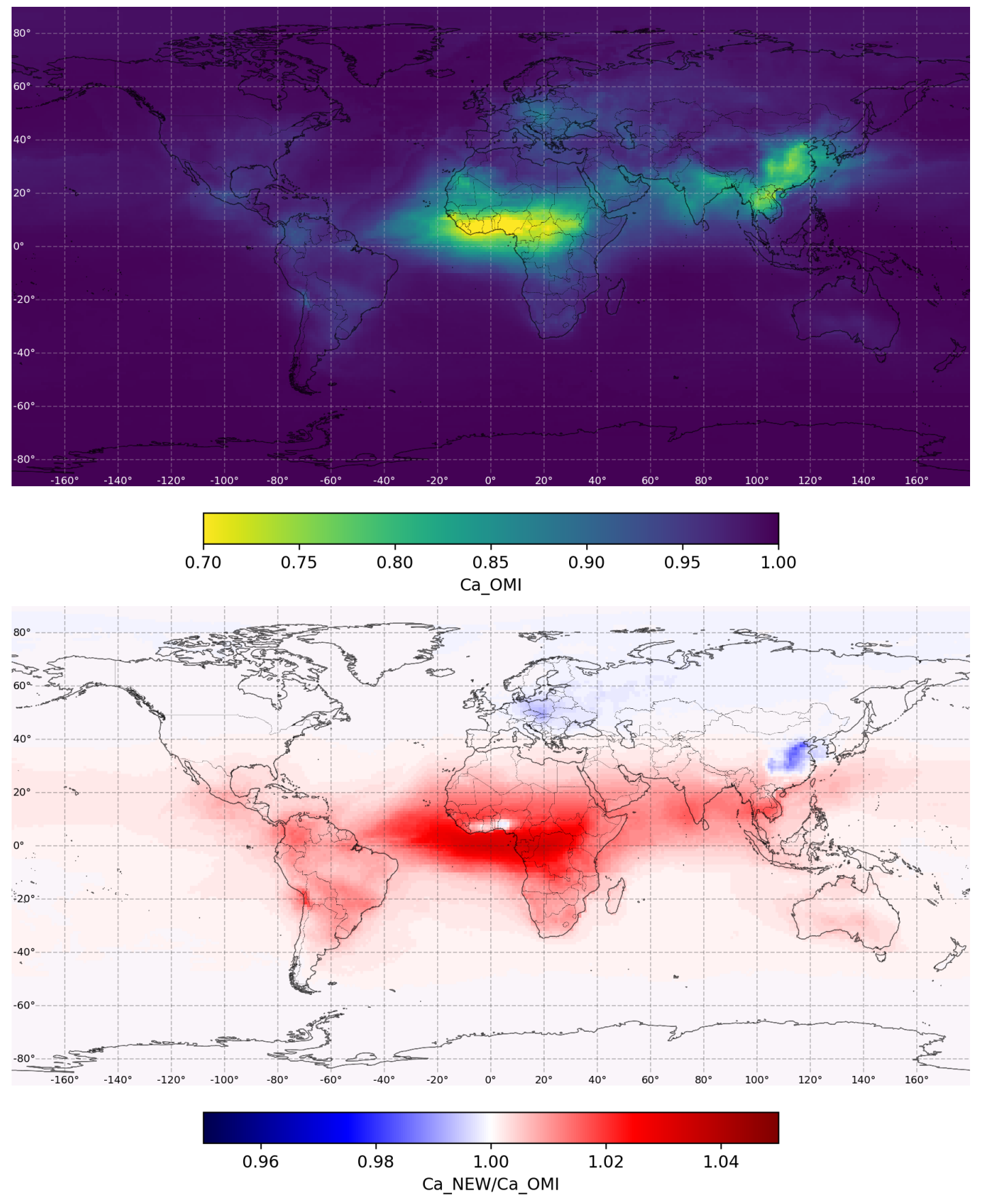

Figure 1: Figure S1: The current operational OMI correction for absorbing aerosols, $C_{a}$ (upper panel). The ratio of the new proposed correction and current operational correction for absorbing aerosols, $C_{a}^{N E W} / C_{a}^{O M I}$ (lower panel). Solar zenith angle corresponds to the noon time conditions on February 15th and aerosol climatology of February is used $_{2}$ 

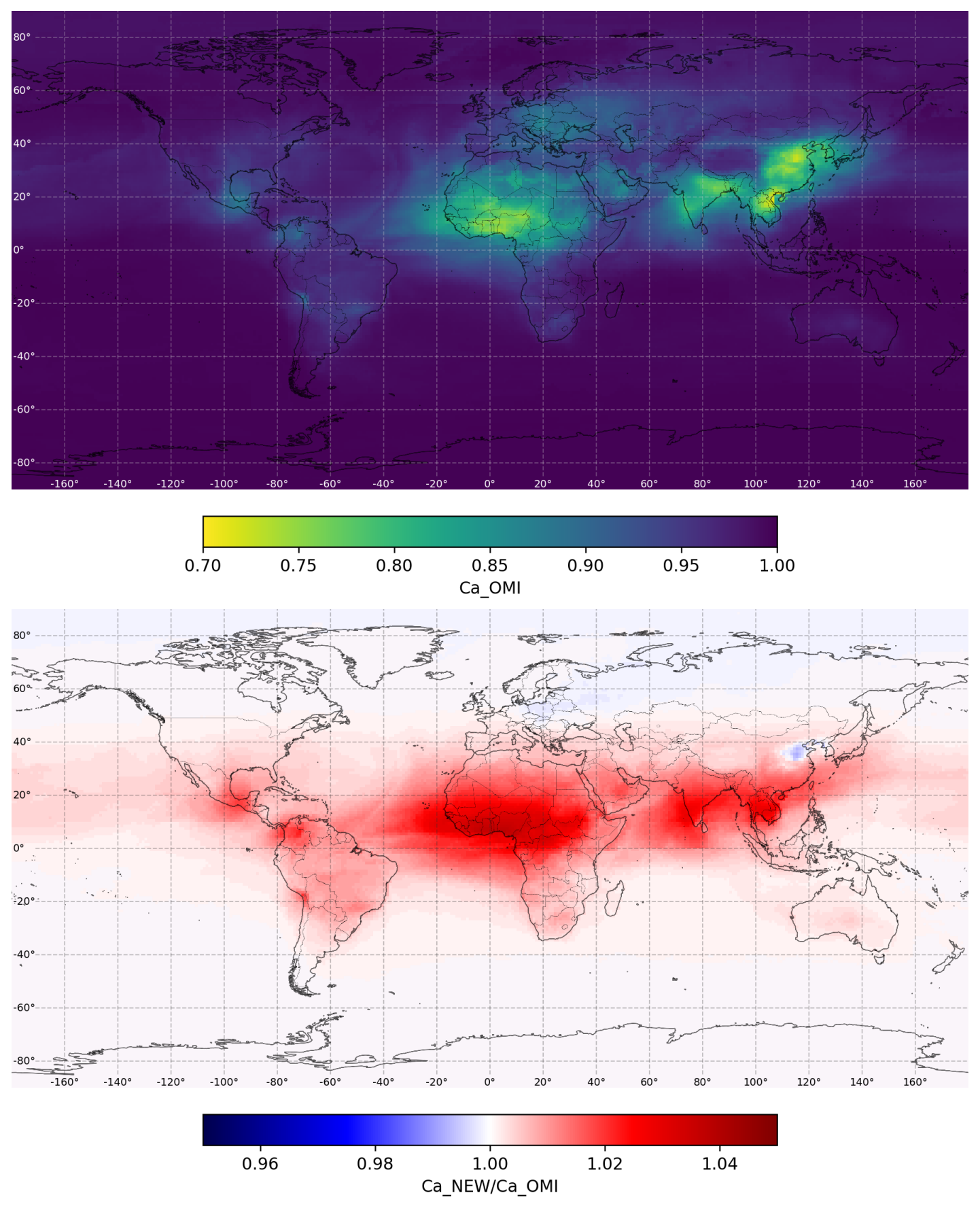

Figure 2: Same as Figure S1, but both SZA and aerosol climatology corresponds to March conditions 

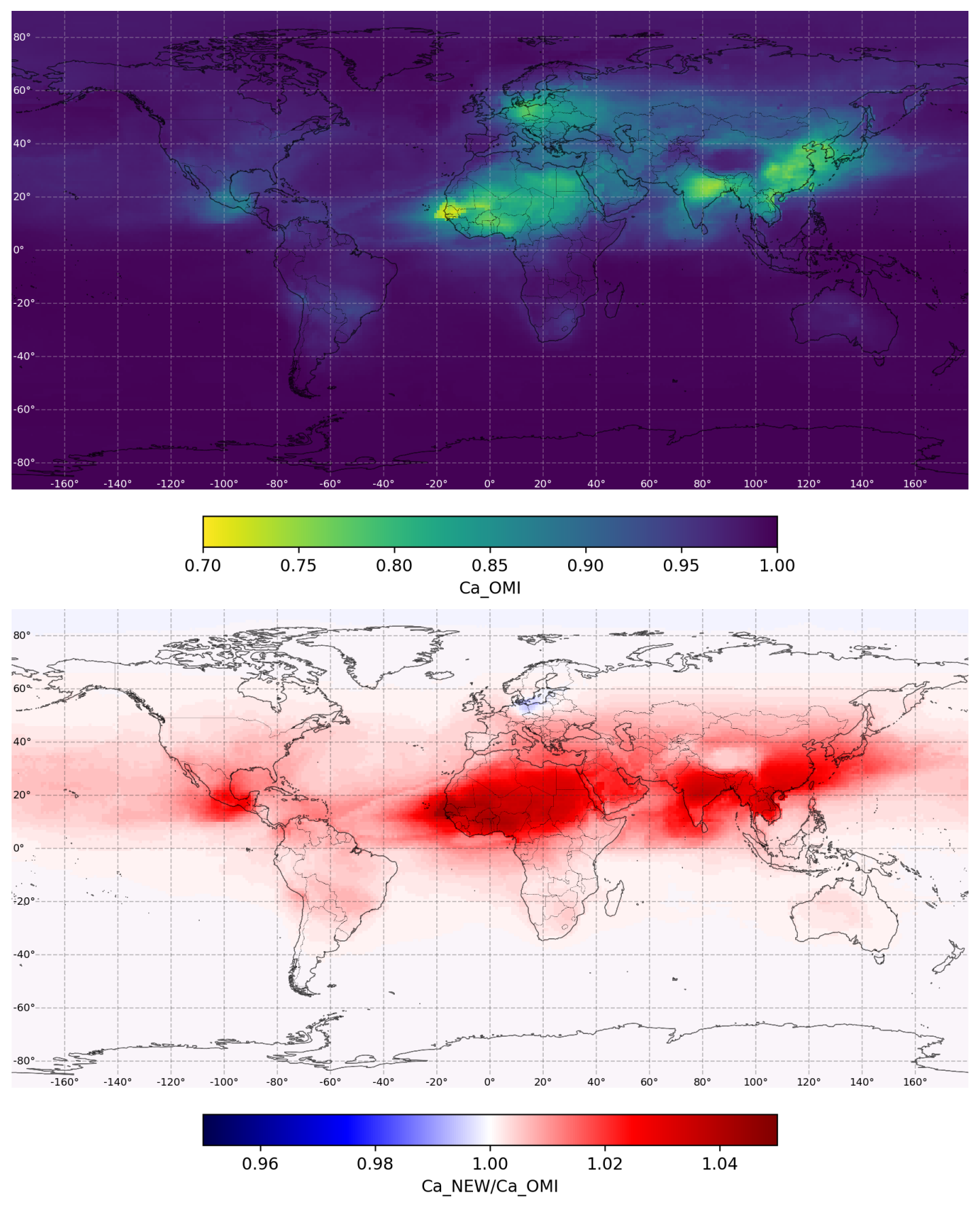

Figure 3: Same as Figure S1, but both SZA and aerosol climatology corresponds to April conditions 

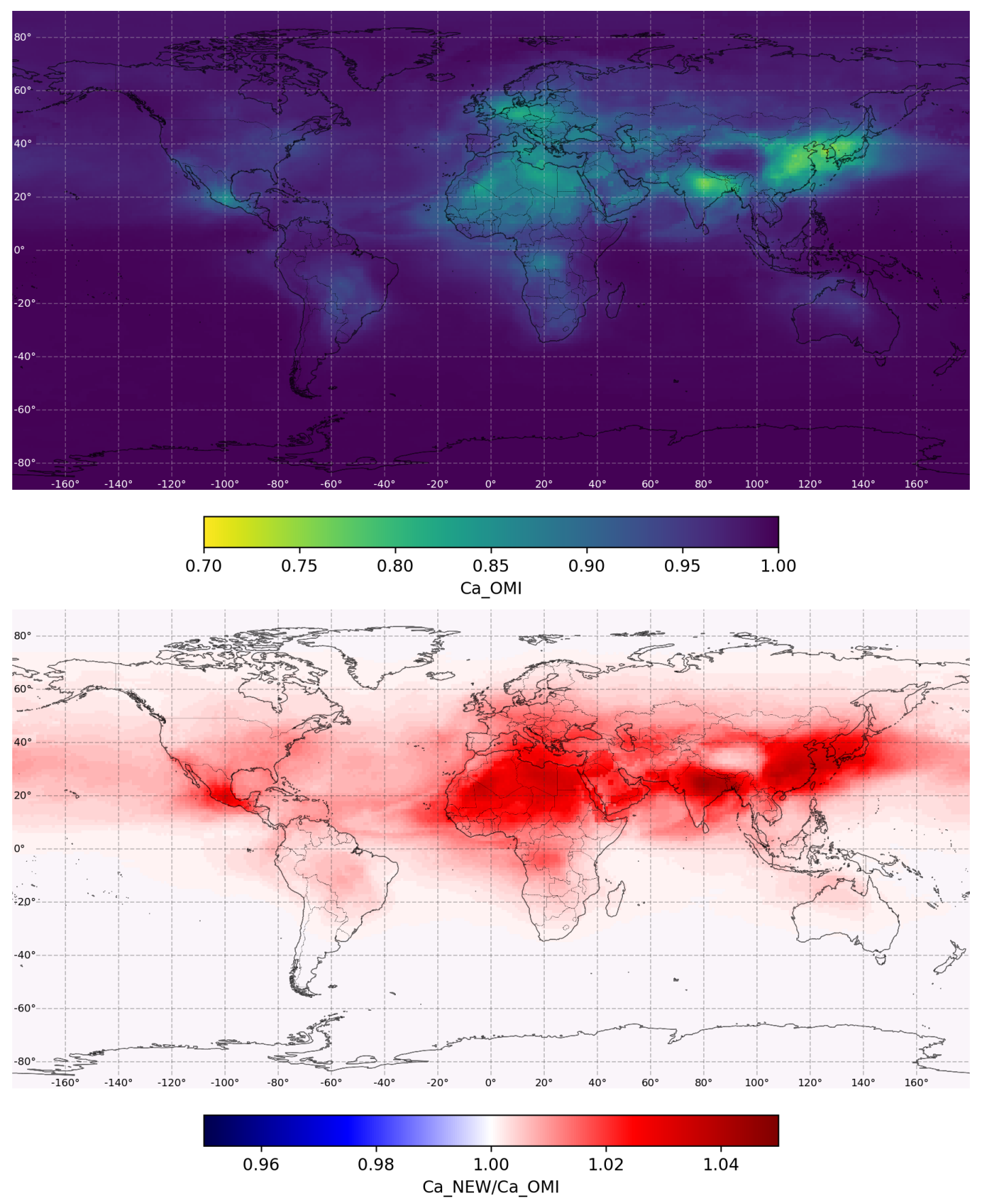

Figure 4: Same as Figure S1, but both SZA and aerosol climatology corresponds to May conditions 

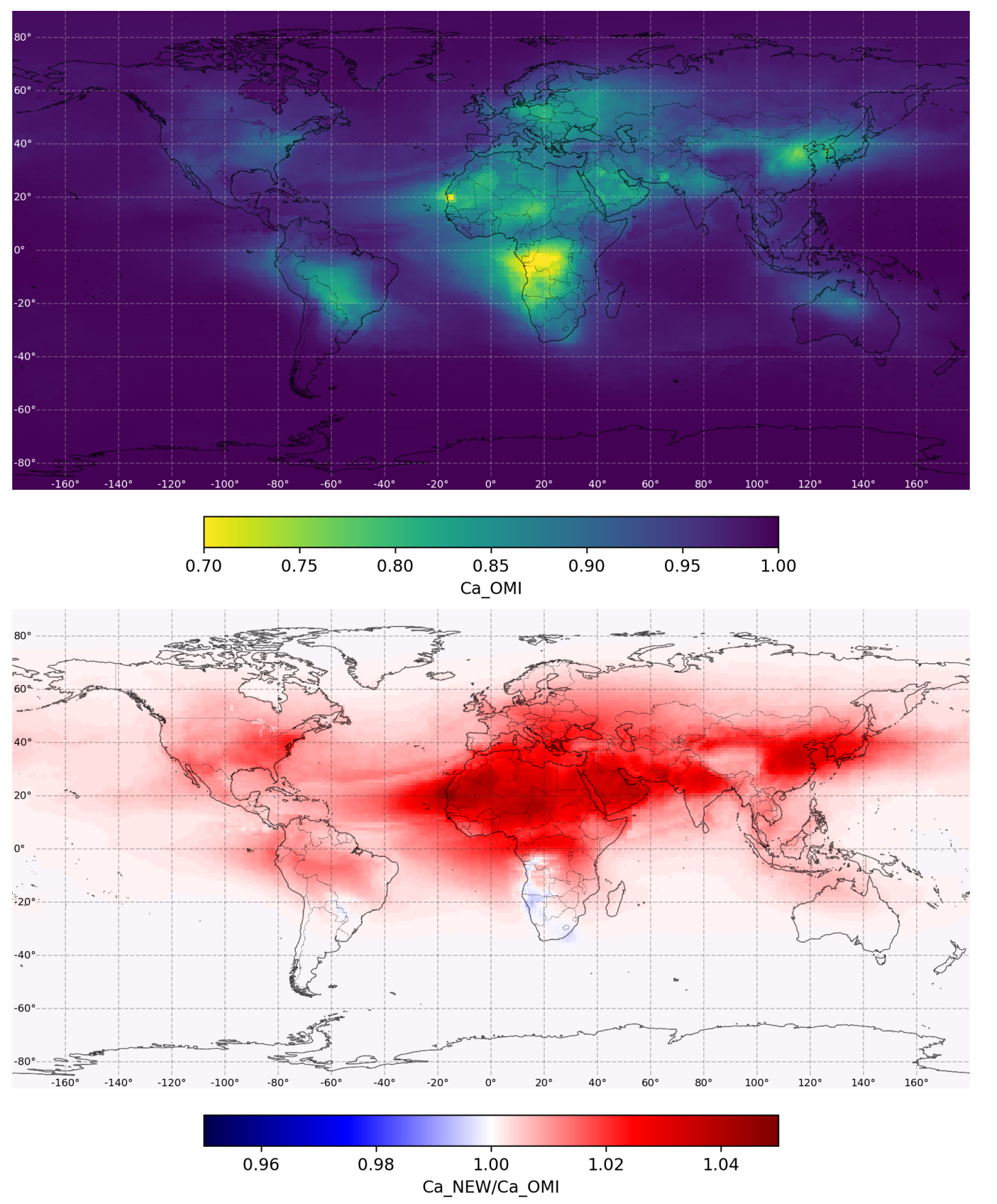

Figure 5: Same as Figure S1, but both SZA and aerosol climatology corresponds to July conditions 

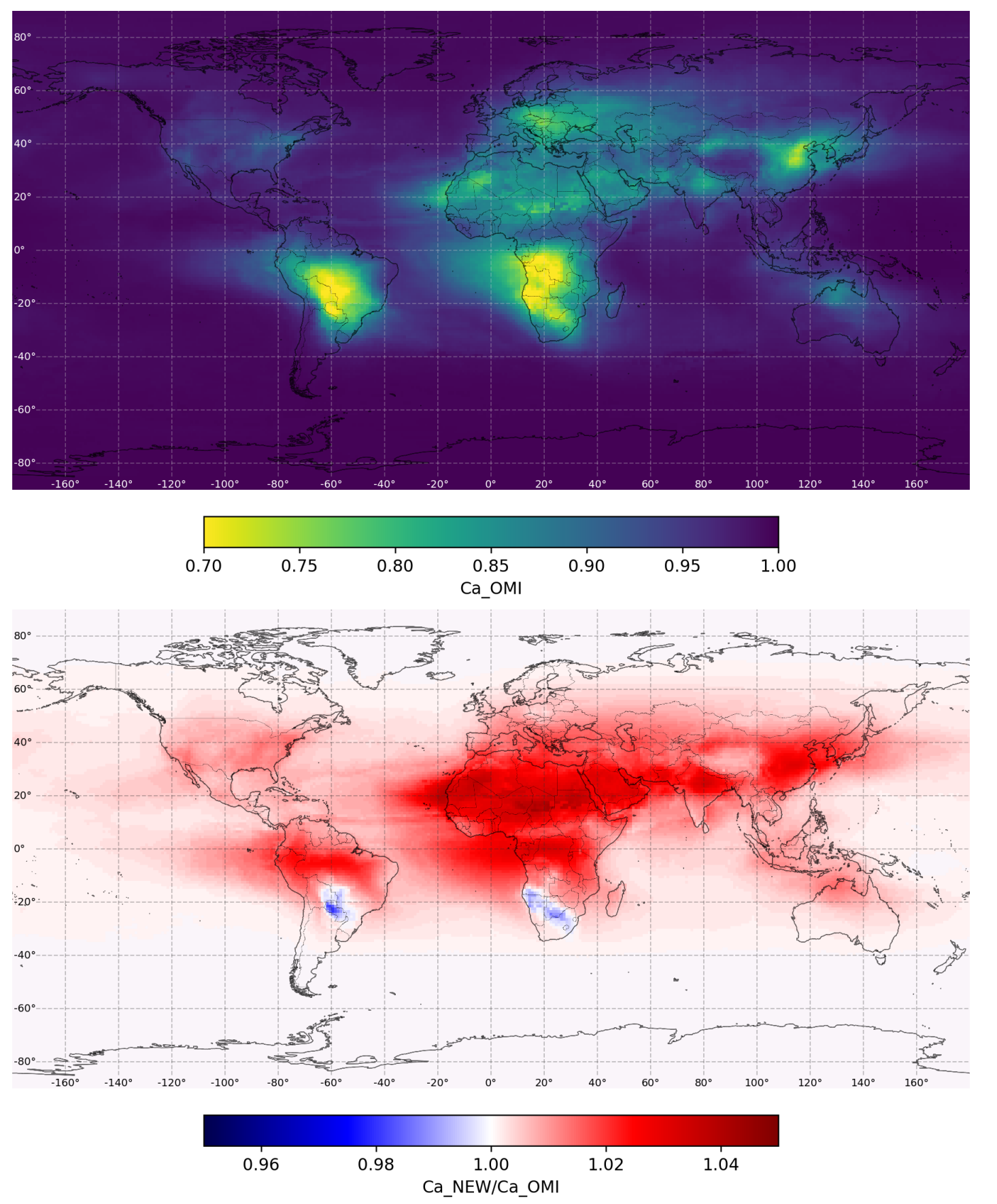

Figure 6: Same as Figure S1, but both SZA and aerosol climatology corresponds to August conditions 

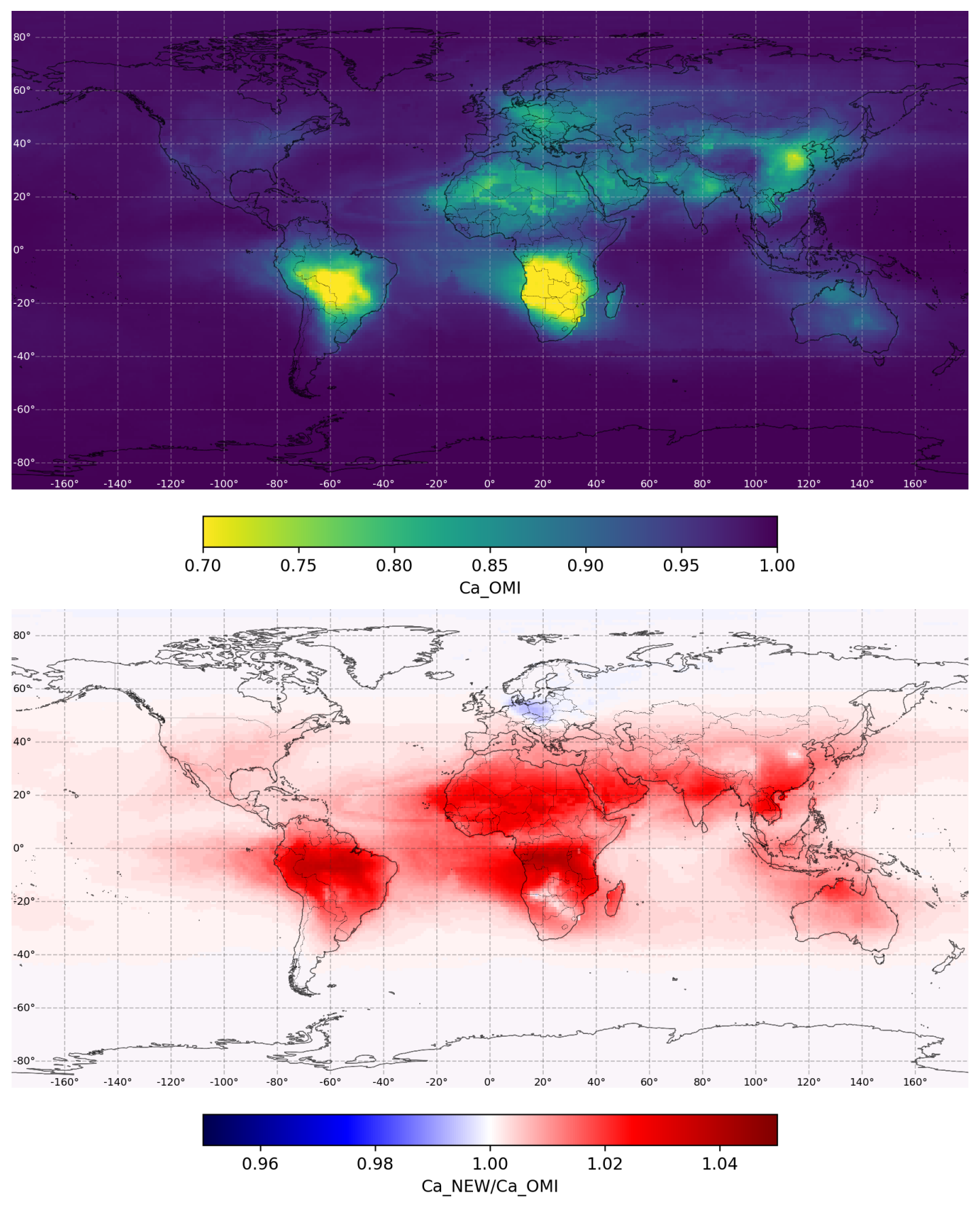

Figure 7: Same as Figure S1, but both SZA and aerosol climatology corresponds to September conditions 

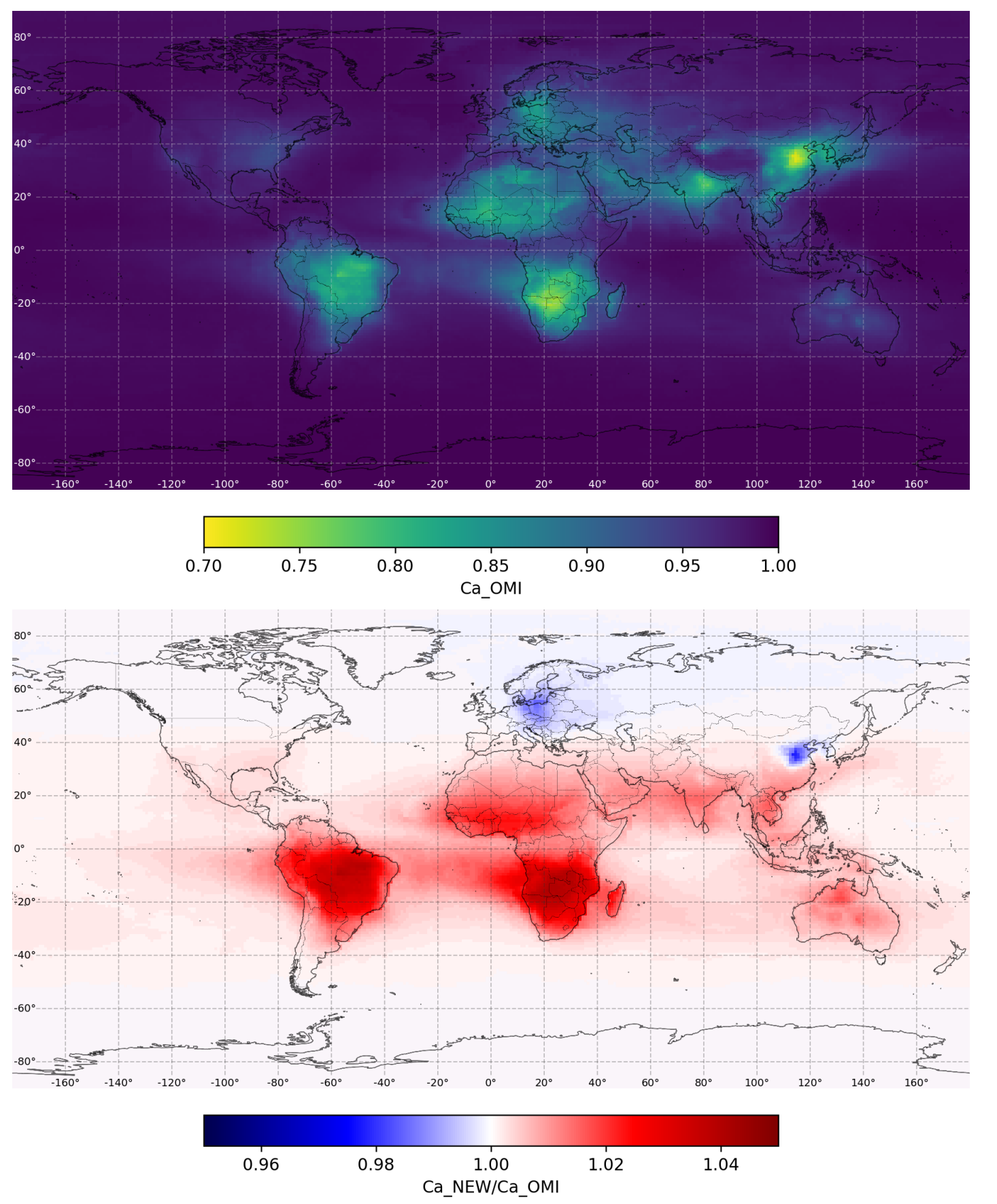

Figure 8: Same as Figure S1, but both SZA and aerosol climatology corresponds to October conditions 

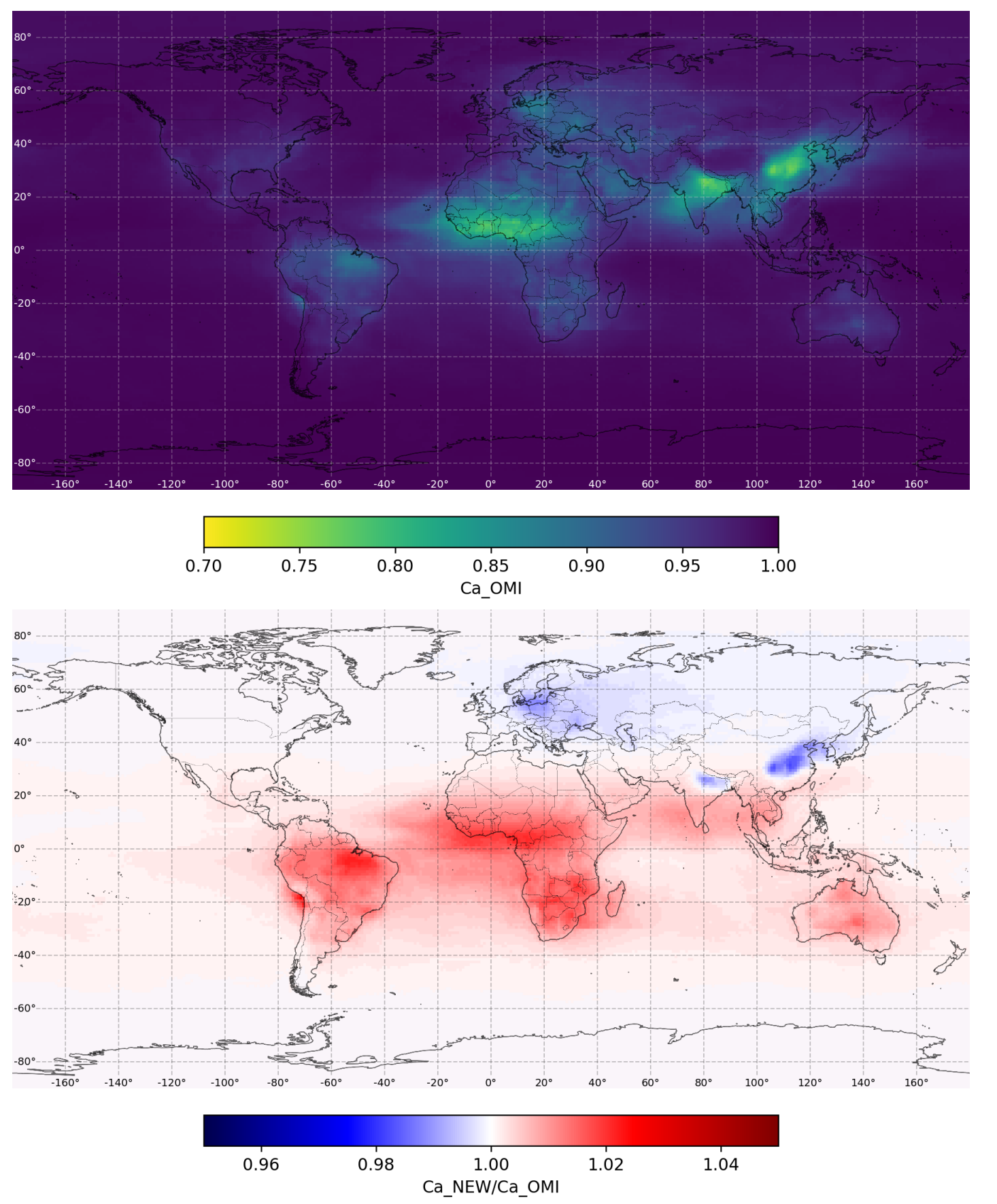

Figure 9: Same as Figure S1, but both SZA and aerosol climatology corresponds to November conditions 

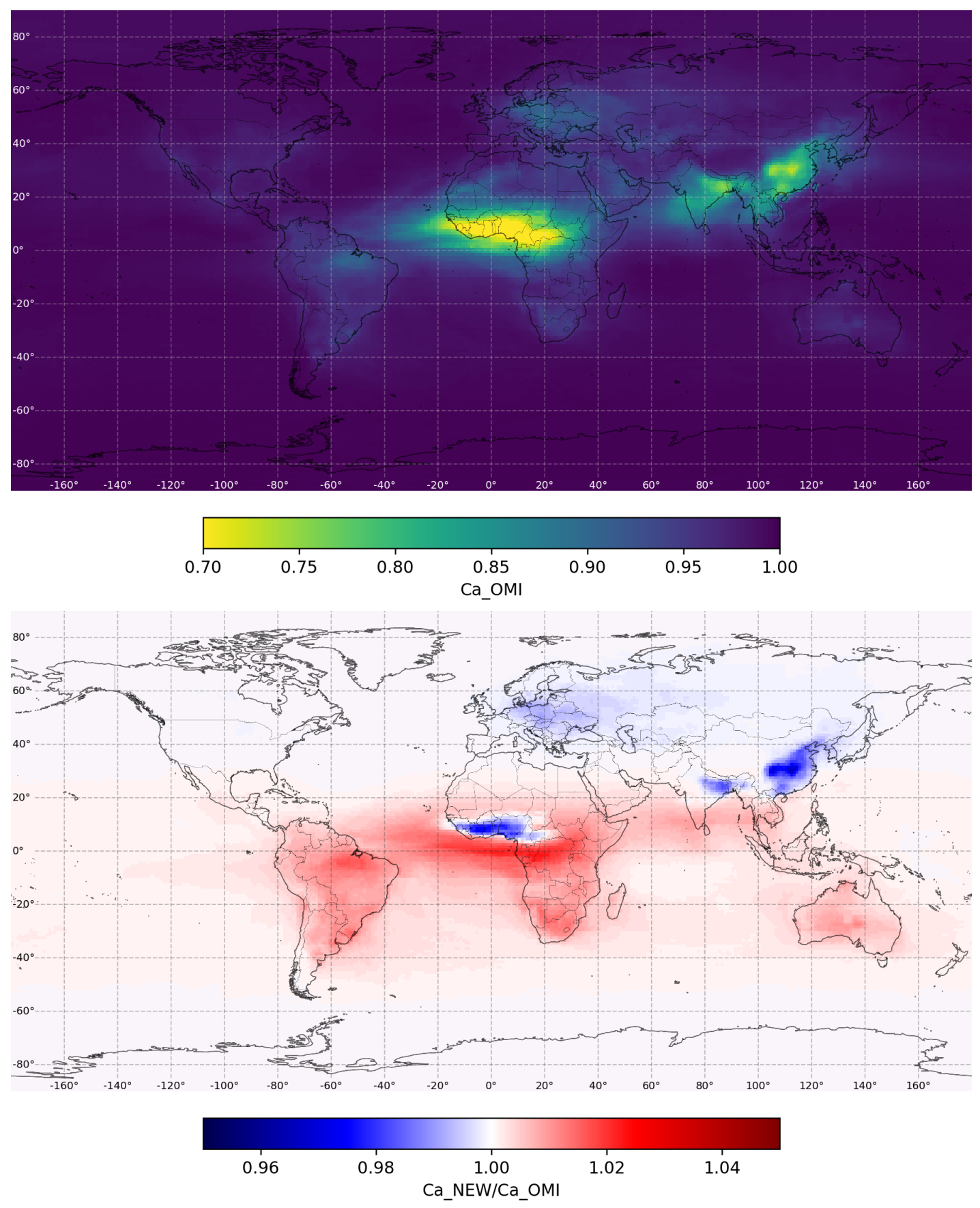

Figure 10: Same as Figure S1, but both SZA and aerosol climatology corresponds to December conditions 